\title{
Angiographic flow grading and graft arrangement of arterial conduits
}

Hiroyuki Nakajima, MD, a Junjiro Kobayashi, MD, ${ }^{\text {a }}$ Osamu Tagusari, MD, ${ }^{a}$ Kazuo Niwaya, MD, ${ }^{\text {a }}$ Toshihiro Funatsu, MD, Atsushi Kawamura, MD, ${ }^{\mathrm{b}}$ Toshikatsu Yagihara, MD, ${ }^{\mathrm{a}}$ and Soichiro Kitamura, MD ${ }^{\mathrm{a}}$

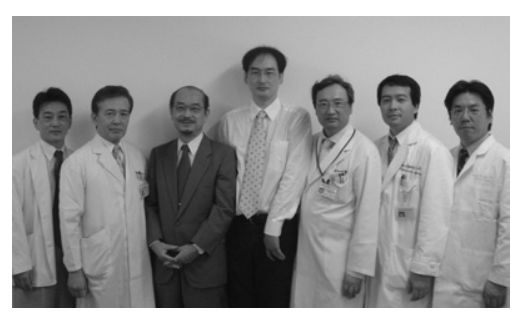

Drs Funatsu, Yagihara, Kitamura, Nakajima, Kobayashi, Tagusari, and Niwaya (left to right)
Objective: We sought to delineate the effects of competitive and reverse flow on the intermediate-term patency of arterial conduits and examined graft arrangements for maximizing antegrade bypass flow.

Methods: The angiograms of 2083 bypass grafts in 570 patients who underwent off-pump total arterial revascularization without aortic manipulation since December 2000 were reviewed. The blood flow in the bypass grafts were graded A (antegrade), B (competitive), C (reverse), or O (occlusion). The mean number of distal anastomoses was $3.65 \pm 0.94$ per patient.

Results: In the early angiography $91.3 \%$ (1901/2083) of the bypasses were grade A. Thirty (1.4\%) bypasses were grade $\mathrm{O}$, whereas $2.9 \%$ (61/2083) were grade $\mathrm{B}$, and 4.4\%(91/2083) were grade C. In the multivariate analysis the end-to-side anastomosis $(P<.0001), 4$ or more distal anastomoses of the conduit $(P=.01)$, native coronary stenosis of less than $75 \%(P<.0001)$, and target branch location of the right coronary artery territory $(P<.0001)$ and left circumflex artery territory $(P=$ .02) significantly correlated with grade non-A. The patency rate in the late angiography of the bypasses graded B or C in the early angiography was $7(28.0 \%)$ of 25 , whereas that of the bypasses graded A was $164(89.1 \%)$ of $184(P<.0001)$. The actuarial graft patency rate of the bypasses graded A was $72.3 \%$ at 3 years and was significantly higher than that of the bypasses graded B or C $(28.6 \%$ at 3 years after surgical intervention, $P<.0001$ ).

Conclusions: The sufficient antegrade bypass flow had a favorable effect on the graft patency of arterial conduits. The graft arrangement should be adjusted for each patient so as to maximize the antegrade bypass flow and to confirm the advantage of arterial grafts.

$\mathrm{T}$ The use of the in situ internal thoracic artery (ITA) graft to the left anterior descending artery (LAD) is widely accepted as a standard strategy that provides long-term patency and improves late survival. The radial artery is also useful as a free graft for coronary artery bypass grafting (CABG). For the radial artery, the graft patency mostly depended on the severity of the native coronary stenosis rather than on the proximal anastomotic site ${ }^{1,2}$ and was equivalent to that of ITA, even when the target coronary branch was small in diameter or had severe atherosclerosis. ${ }^{3,4}$

In the bypass conduits having 2 or more distal anastomoses, dominant reversal flow is not quite rare. Because the bypass grafts with reverse flow do not contribute to the coronary perfusion in the grafted territory, the efficacy of CABG might be unpromising, even when the bypass graft is anatomically patent. In addition, as a consequence of inappropriate graft flow, graft failure, such as diffuse narrowing or occlusion, can occur because it has been reported that the arterial materials have shown adaptability of their own diameter to the circumstances of the blood flow in the graft lumen. ${ }^{5-9}$ 

Abbreviations and Acronyms
$\mathrm{CABG}=$ coronary artery bypass grafting
ITA $=$ internal thoracic artery
$\mathrm{LAD}=$ left anterior descending artery
LCX $=$ left circumflex artery
RCA = right coronary artery

Despite the various graft configurations that have previously been reported, ${ }^{10-12}$ the optimal strategy for graft arrangement remains unknown. Because an excellent early graft patency rate can be highly expected when arterial graft materials are exclusively used, the patency rate of the bypass grafts might not necessarily be useful for evaluation and comparison of the graft arrangements.

The objectives of this study were to delineate the effect of the graft flow in the sequential and composite arterial grafts on the late graft patency and to establish the optimal strategy for the graft arrangement of the arterial conduits for minimizing competitive and reverse flow.

\section{Materials and Methods}

The coronary angiograms of 570 patients who underwent offpump coronary revascularization with single or bilateral ITA grafts and the radial artery without aortic manipulation between December 2000 and June 2005 were reviewed. There were 475 men and 95 women with a mean age of $66.0 \pm 9.3$ years (Table 1 ), and all patients provided written informed consent. These patients were consecutive after eliminating those who had a bypass of the saphenous vein, gastroepiploic artery, or inferior epigastric artery; underwent no early postoperative coronary angiography; or had bypass grafting in an individual fashion only. During the same

\section{TABLE 1. Baseline characteristics}

\begin{tabular}{ll}
\hline No. of patients & 570 \\
Age (y) & $66.0 \pm 9.3$ \\
Male/female sex & $475 / 95$ \\
Hypertension & $301(52.8 \%)$ \\
Hyperlipidemia & $270(48.9 \%)$ \\
Diabetes & $218(38.2 \%)$ \\
Left ventricular end-diastolic volume index & $86.2 \pm 29.7$ \\
$\quad$ (mL/m²) & \\
Left ventricular ejection fraction (\%) & $47.8 \pm 11.9$ \\
Total distal anastomoses & 2083 \\
Distal anastomoses per patient & $3.65 \pm 0.95$ \\
Bypass conduits used & 830 \\
Individual in situ ITA & 151 \\
Individual composite I-graft & 28 \\
Composite Y-graft & 358 \\
Composite I-graft & 173 \\
Composite K-graft & 63 \\
In situ ITA sequential & 57 \\
\hline
\end{tabular}

ITA, Internal thoracic artery.
TABLE 2. Concept of flow grading system

\begin{tabular}{lllll}
\hline & \multicolumn{4}{c}{ Grade } \\
\cline { 2 - 5 } & \multicolumn{1}{c}{ A } & \multicolumn{1}{c}{ B } & C & 0 \\
\hline Flow direction & Antegrade & Competitive Reverse & No-flow \\
Patency & Patent & Patent & Patent & Occluded \\
Function & Functioning & Functioning & Nonfunction & Nonfunction \\
Durability & Durable (?) (?) & (?) & No \\
\hline
\end{tabular}

$A$, Antegrade; $B$, competitive; $C$, reverse; 0 , occlusion.

period, off-pump CABG was performed for 821 patients. Early coronary angiography was performed for all 570 patients at about 2 weeks after the operation. The native coronary artery stenosis and the graft patency were independently evaluated by cardiologists. The degrees of stenosis in the precise measurement of the luminal diameter were graded as $51 \%$ to $75 \%, 76 \%$ to $90 \%$, and $91 \%$ to $100 \%$. The maximal severity of stenosis was recorded for all coronary branches.

The definitions of terms in the present study are as follows. An in situ ITA graft is an ITA that was divided only at its distal portion. A composite graft is a bypass conduit consisting of one in situ graft and a free graft anastomosed to it (in end-to-end, endto-side, or side-to-side fashion). A combination of Y-grafts, $\mathrm{K}$ grafts, and I-grafts and the individual conduit were used in this study. An individual bypass was defined as a conduit having one distal anastomosis and one in situ graft. This included an in situ graft that was extended by a free graft and bypassed to one target coronary branch. A bypass conduit having one in situ graft and 2 or more distal anastomoses, such as a sequential graft or a composite Y-graft (or K-graft), was defined as nonindividual.

\section{Flow Grading}

The concept of determining grading of the graft flow focused on 2 factors: (1) the function as a blood supply to the ischemic myocardium and (2) the possibility of graft failure in the future (Table 2). A patent graft meant that the graft had a complete continuity of the graft lumen in the overall length from the subclavian artery to the anastomotic site with the coronary branch, irrespective of the flow direction. When the continuity of the graft lumen from an in situ ITA graft to the anastomosis with the target coronary branch was interrupted at any level, it was defined as grade $\mathrm{O}$ (occlusion), which was regarded as a no-flow situation with closure of the lumen of the bypass graft. Grade A was defined as a situation in which antegrade graft flow (ie, from the in situ graft to the target coronary branch) was found in most of the multiplane ITA angiography. Grade B (competitive) was defined as a situation in which the target vessel was barely opacified from the ITA graft injection and the bypass graft was filled by retrograde flow from the native coronary injection. In the worst of multiplane angiography, the contrast medium from the in situ ITA did not surely reach the target branch. Grade $\mathrm{C}$ (reverse) was defined as a situation in which the distal anastomotic site was not opacified from the ITA graft injection at all but was filled clearly by retrograde flow from the native coronary injection. The difference between grades $\mathrm{B}$ and $\mathrm{C}$ was whether the contrast medium from the in situ ITA finally reached the target branch in the best frame of multiplane examinations. Grades $\mathrm{C}$ and $\mathrm{O}$ meant that the bypass 
TABLE 3. Early angiographic results

\begin{tabular}{|c|c|c|c|c|c|c|}
\hline & \multirow{2}{*}{$\begin{array}{l}\text { Characteristics of } \\
\text { coronary branches }\end{array}$} & \multirow{2}{*}{$\begin{array}{c}\text { No. of } \\
\text { anastomoses }\end{array}$} & \multicolumn{4}{|c|}{ Grade } \\
\hline & & & A (\%) & B $(\%)$ & C $(\%)$ & $0(\%)$ \\
\hline \multirow[t]{4}{*}{ Location } & LAD main trunk & 574 & $541(94.3)$ & $17(3.0)$ & $11(1.9)$ & $5(0.9)$ \\
\hline & Diagonal & 314 & $296(94.3)$ & $7(2.2)$ & $7(2.2)$ & $4(1.3)$ \\
\hline & LCX & 646 & $587(90.9)$ & $15(2.3)$ & $35(5.4)$ & $9(1.4)$ \\
\hline & RCA & 549 & 477 (86.9) & $22(4.0)$ & $38(6.9)$ & $12(2.2)$ \\
\hline \multirow[t]{3}{*}{ Stenosis } & $51 \%-75 \%$ & 957 & $815(85.2)$ & $53(5.5)$ & $76(7.9)$ & $13(1.4)$ \\
\hline & $76 \%-90 \%$ & 553 & $521(94.2)$ & $8(1.4)$ & $15(2.7)$ & $9(1.6)$ \\
\hline & $91 \%-100 \%$ & 573 & $565(98.6)$ & 0 & 0 & $8(1.4)$ \\
\hline Overall & - & 2083 & 1901 (91.3) & $61(2.9)$ & $91(4.4)$ & $30(1.4)$ \\
\hline
\end{tabular}

$A$, Antegrade; $B$, competitive; $C$, reverse; 0 , occlusion; $L A D$, left anterior descending artery; $L C X$, left circumflex artery; $R C A$, right coronary artery.

graft did not contribute to the increase of coronary perfusion in the grafted territory. Grade B bypass grafts probably contributed to the coronary perfusion, but the durability of graft patency was considered uncertain because the retrograde flow from the native coronary branch was almost comparable with that of grade $\mathrm{C}$. The flow grade was recorded for each target coronary branch.

\section{Graft Selection and Strategy}

The details of our standard technique and pharmacologic management were reported previously. ${ }^{13}$ The bilateral ITAs were preferably used for patients aged less than 75 years with neither severe chronic obstructive pulmonary disease nor diabetes requiring insulin therapy for improvement of the late outcome. ${ }^{11,14-16}$ All of the ITA grafts in the present series had a luminal diameter of 1.5 $\mathrm{mm}$ or larger. In the side-to-side anastomosis we made a longitudinal incision of approximately 6 to $10 \mathrm{~mm}$ in the native coronary artery and arterial graft to achieve a sufficient luminal size without turbulence. The angle of placement of the graft was adjusted to save the graft length and avoid kinking.

The various configurations of the bypass conduits used in our patients are listed in Table 1. The arrangement of the bypass conduits was determined primarily on the basis of the special relationship of the target coronary arteries. Since March 2003, we have introduced our current strategy. Our current graft arrangement consisted of the left ITA to LAD grafting concomitant with an I-graft of the right ITA and radial artery to the left circumflex artery (LCX) and right coronary artery (RCA) in a sequential fashion. In addition, we selected appropriate orientation (clockwise or counter clockwise) to avoid bypass grafting to a coronary branch with $51 \%$ to $75 \%$ stenosis at the end of the I-graft as much as possible because the terminal end of the conduit was commonly associated with reverse flow. ${ }^{13,17}$ Before March 2003, the I-graft was used only in a counterclockwise orientation for all patients.

\section{Early Angiography of $\mathbf{2 0 8 3}$ Coronary Branches}

To determine the factors that predicted the grade non-A bypass grafts in the early angiography, we collected detailed data regarding the target coronary branch, the bypass conduit, and anastomotic fashion. The variables in the univariate analysis included the territory of the target coronary branch (LAD, LCX, or RCA), the diameter $(1.0,1.25,1.5$, or $2.0 \mathrm{~mm}$, as determined by the intracoronary shunt used), the severity of the native coronary stenosis
( $51 \%$ to $75 \%$ or $76 \%$ to $100 \%$ ), the kind of graft material (in situ ITA, free ITA, or radial artery), the type of conduit (in situ ITA, Y-graft, K-graft, or I-graft), the number of distal anastomoses of the conduit ( 3 or less, or 4 or more), and the type of anastomoses (end-to-side or side-to-side).

\section{Analysis of Clinical Outcome in 570 Patients}

We examined the effects of the bilateral in situ ITA grafts, total distal anastomotic sites, vessel disease, presence (or absence) of bypass graft grade non-A in the early angiography, and day of the operation in the period of our current strategy of graft arrangement. The mean follow-up period was $22 \pm 16$ months.

\section{Statistical Analysis}

The continuous variables are expressed as the mean values \pm standard deviation. The univariate and multivariate analyses were performed by using the logistic regression method. The KaplanMeier method was used to determine the actuarial graft patency rate. Cox regression analysis was used to examine the significance of the clinical and angiographic variables in predicting the cardiac event-free time.

\section{Results}

The results of analysis of 2083 anastomoses are shown in Table 3. The overall early patency rate was $2053(98.6 \%)$ of 2083. Sixty-one $(2.9 \%)$ bypasses were graded B, $91(4.4 \%)$ were graded C, and 1901 (91.2\%) were graded A.

In the univariate analysis, the end-to-side anastomosis $(P$ $<.0001$ ), conduit type (Y-graft, $P=.002$; K-graft, $P=$ .002 ; I-graft, $P=.02$ ), native coronary stenosis of less than 75\% $(P<.0001)$, location (RCA territory, $P<.0001$; LCX territory, $P=.02$ ), and graft material (radial artery, $P=$ .04) were correlated with grade non-A. In the multivariate analysis, the end-to-side anastomosis $(P<.0001), 4$ or more distal anastomoses of the conduit $(P=.01)$, native coronary stenosis of less than $75 \%(P<.0001)$, and target branch location (RCA territory, $P<.0001$; LCX territory, $P=.02$ ) significantly correlated with grade non-A (Table 4). Neither the type of the conduit nor the graft material 
TABLE 4. Predictors of grade non-A in the early angiography

\begin{tabular}{|c|c|c|c|}
\hline Variables & Odds ratio & $95 \% \mathrm{CI}$ & $P$ value \\
\hline \multicolumn{4}{|l|}{ Univariate analysis } \\
\hline End-to-side anastomosis & 4.51 & $2.88-7.04$ & $<.0001$ \\
\hline $\begin{array}{l}\text { Distal anastomoses of } \\
\text { conduit }>3\end{array}$ & 1.27 & $0.92-1.76$ & .14 \\
\hline $\begin{array}{l}\text { Type of conduit, } \\
\text { Y-graft (vs in situ ITA) }\end{array}$ & 2.80 & $1.44-5.43$ & .002 \\
\hline $\begin{array}{l}\text { Type of conduit, } \\
\text { K-graft (vs in situ ITA) }\end{array}$ & 3.21 & $1.52-6.78$ & .002 \\
\hline $\begin{array}{l}\text { Type of conduit, } \\
\text { I-graft (vs in situ ITA) }\end{array}$ & 2.30 & $1.14-4.68$ & .02 \\
\hline $51 \%-75 \%$ stenosis & 4.73 & $3.29-5.80$ & $<.0001$ \\
\hline $\begin{array}{l}\text { Location, RCA territory } \\
\text { (vs LAD territory) }\end{array}$ & 2.51 & $1.73-3.65$ & $<.0001$ \\
\hline $\begin{array}{l}\text { Location, LCX territory } \\
\text { (vs LAD territory) }\end{array}$ & 1.62 & $1.10-2.40$ & .02 \\
\hline $\begin{array}{l}\text { Graft material, free ITA } \\
\text { (vs in situ ITA) }\end{array}$ & 0.98 & $0.29-3.28$ & .97 \\
\hline $\begin{array}{l}\text { Graft material, free RA } \\
\text { (vs in situ ITA) }\end{array}$ & 1.44 & $1.02-2.03$ & .04 \\
\hline $\begin{array}{l}\text { Diameter of coronary } \\
\text { branch }\end{array}$ & 0.62 & $0.23-1.69$ & .35 \\
\hline \multicolumn{4}{|l|}{ Multivariate analysis } \\
\hline End-to-side anastomosis & 8.18 & $4.82-13.87$ & $<.0001$ \\
\hline $\begin{array}{l}\text { Distal anastomoses of } \\
\text { conduit }>3\end{array}$ & 1.73 & $1.17-2.55$ & .01 \\
\hline $\begin{array}{l}\text { Type of conduit, } \\
\text { Y-graft (vs in situ ITA) }\end{array}$ & 1.91 & $0.91-4.05$ & .09 \\
\hline $\begin{array}{l}\text { Type of conduit, } \\
\text { K-graft (vs in situ ITA) }\end{array}$ & 1.71 & $0.70-4.17$ & .24 \\
\hline $\begin{array}{l}\text { Type of conduit, } \\
\text { l-graft (vs in situ ITA) }\end{array}$ & 1.77 & $0.76-4.14$ & .19 \\
\hline $51 \%-75 \%$ stenosis & 6.19 & $4.22-9.09$ & $<.0001$ \\
\hline $\begin{array}{l}\text { Location, RCA territory } \\
\text { (vs LAD territory) }\end{array}$ & 3.49 & $1.82-6.69$ & .0002 \\
\hline $\begin{array}{l}\text { Location, LCX territory } \\
\text { (vs LAD territory) }\end{array}$ & 3.15 & $1.71-5.81$ & .0002 \\
\hline $\begin{array}{l}\text { Graft material, free ITA } \\
\text { (vs in situ ITA) }\end{array}$ & 0.60 & $0.15-2.35$ & .46 \\
\hline $\begin{array}{l}\text { Graft material, free RA } \\
\text { (vs in situ ITA }\end{array}$ & 0.89 & $0.47-1.72$ & .73 \\
\hline
\end{tabular}

$\overline{C l}$, Confidence interval; ITA, internal thoracic artery; $R C A$, right coronary artery; $L A D$, left anterior descending artery; $L C X$, left circumflex artery; $R A$, radial artery.

anastomosed with the coronary branch correlated with grade non-A.

\section{Intermediate-term Results}

In the follow-up period 10 patients died (cardiac death, 8; stroke, 2). Repeated angiography was carried out for 216 bypass grafts in 61 patients, who had some symptoms, including angina, or an ischemic region detected by means
TABLE 5. Early and late angiographic results of 216 bypass grafts

\begin{tabular}{lrrrc}
\hline & & \multicolumn{3}{c}{ Late angiography } \\
\cline { 3 - 5 } $\begin{array}{l}\text { Flow grade in early } \\
\text { angiography }\end{array}$ & $\begin{array}{c}\text { Bypass } \\
\text { grafts }\end{array}$ & Patent & Occluded & $\begin{array}{c}\text { Patency rate } \\
\text { (\%) }\end{array}$ \\
\hline A & 184 & 164 & 20 & 89.1 \\
B & 12 & 4 & 8 & 33.3 \\
C & 13 & 3 & 10 & 23.1 \\
0 & 7 & 0 & 7 & 0.0 \\
Total & 216 & 171 & 45 & 79.2 \\
\hline
\end{tabular}

$A$, Antegrade; $B$, competitive; $C$, reverse; 0 , occlusion.

of electrocardiography or scintigraphy. Thirty-eight patients underwent percutaneous coronary intervention. The early and late angiographic results of these 216 bypass grafts are shown in Table 5. The patency rate in the late angiography of bypasses that were graded $\mathrm{B}$ or $\mathrm{C}$ in the early angiography was $7(28.0 \%)$ of 25 , whereas that of bypasses graded A was $164(89.1 \%)$ of $184(P<.0001)$.

The actuarial graft patency rates at 3 years were $72.3 \%$ for bypasses graded A and $28.6 \%$ for bypasses graded B or $\mathrm{C}(P<.0001$, Figure 1$)$. There was no significant difference between grades $\mathrm{B}$ and $\mathrm{C}$ in the actuarial graft patency rate $(P=.20)$. The multivariate Cox regression analysis demonstrated that the presence of bypass grafts graded non-A ( $P$ $=.007)$ was a significant predictor of cardiac events in the intermediate-term outcome, and the period (March 2003June 2005) was inversely correlated $(P=.008$; odds ratio, 0.32 , Table 6).

\section{Discussion}

A composite graft, which consists of the left ITA and radial artery, provided total arterial revascularization with an excellent graft patency rate and less incidence of late cardiac events compared with those seen with conventional CABG. ${ }^{18,19}$ Various arrangements of the in situ and free arterial grafts have already been practiced and reported. ${ }^{10-12}$ Because an excellent early patency rate with less incidence of complications can be highly expected when arterial graft materials are exclusively used, the optimal strategy for graft arrangement remains unknown. For comparison of these graft arrangements and establishment of the optimal strategy, it is necessary to assess this with criteria more specific than "patent" or "occluded."

The angiographic luminal size, which was reported by FitzGibbon and colleagues, ${ }^{20,21}$ might not be feasible for evaluation of arterial graft arrangements. At first, the luminal size of the anastomotic site is not precisely measurable in the sequential fashion, especially when the angle of the graft and coronary branch is near $90^{\circ}$ or when the contrast medium fills only incompletely because of mixture with the blood flow from the native coronary artery. Additionally, 


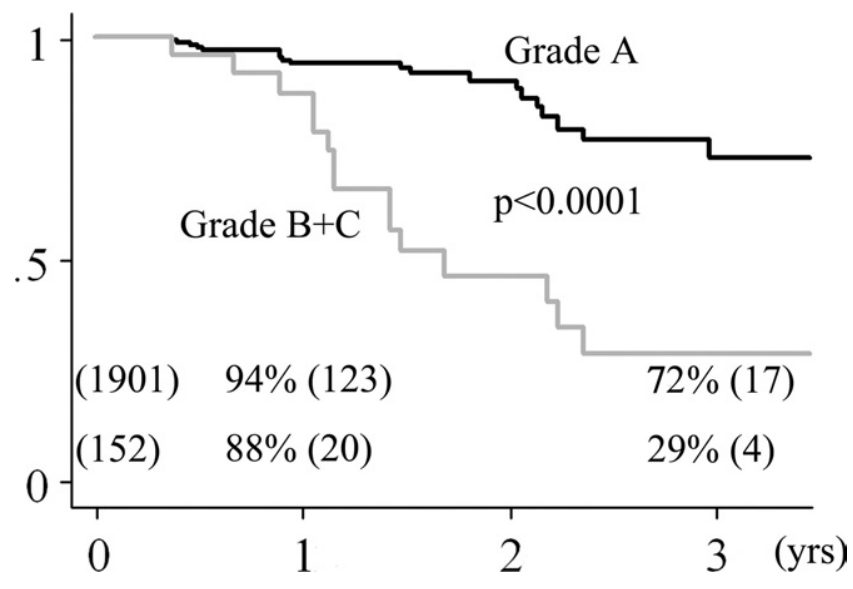

Figure 1. The actuarial graft patency rate.

inadequate surgical maneuvers during the operation can also strongly affect the luminal size as a result of unsuccessful anastomosis or graft kinking. Furthermore, regression of the stenosis and increase or growth of the diameter were relatively common findings in the arterial grafts. ${ }^{22,23}$ There were 2 issues associated with insufficient bypass flow in the arterial conduits. These might be potential disadvantages of the strategy with aorta no-touch off-pump CABG using totally arterial grafts. One issue is the subject of bypass function as a blood supply to the myocardial tissue. A bypass graft presenting reverse flow, which means an obviously dominant native coronary flow, will not increase the blood supply to the myocardium in the region of the grafted coronary branch. We previously reported that not only the severity of the native coronary stenosis but also the interactions of the target coronary branches, which were connected with a composite Y-graft or sequential anastomoses, played a crucial role in the occurrence of reverse flow. ${ }^{13,17}$ Our current graft arrangement was established to avoid development of graft nonfunction.

The other issue is the thinning or closure of the graft lumen in the postoperative period. If the flow velocity is extremely low, even when its direction is antegrade, the bypass graft might not be durable. Previously, there have been a few studies of early and late angiographies concerning physiologic characteristics of arterial grafts but only in small series. ${ }^{7-9}$ Hashimoto and associates ${ }^{8}$ reported serial changes of 53 arterial grafts in 38 patients after conventional $\mathrm{CABG}$ and demonstrated a significant correlation between "the severity of the native coronary stenosis" and "arterial graft thinning" in the early and follow-up angiographies.

In the present study it was necessary for us to demonstrate the effect of the graft flow in the composite and sequential grafts on graft patency and clinical outcomes and
TABLE 6. Predictors of cardiac events in $\mathbf{5 7 0}$ patients

\begin{tabular}{lccc}
\hline Variables & Odds ratio & 95\% Cl & $\boldsymbol{P}$ value \\
\hline $\begin{array}{l}\text { Univariate analysis } \\
\quad \text { Total distal anastomoses }\end{array}$ & 1.04 & $0.77-1.40$ & .82 \\
$\quad$ Period, March & 0.30 & $0.13-0.70$ & .005 \\
$\quad$ 2003 June 2005 & & & \\
$\quad$ Bilateral in situ ITA & 1.10 & $0.61-1.97$ & .76 \\
$\quad$ Presence of grade non-A & 1.97 & $1.12-3.45$ & .02 \\
$\quad$ Vessel disease & 1.02 & $0.61-1.69$ & .94 \\
$\quad$ Ejection fraction $<40 \%$ & 1.78 & $0.95-3.30$ & .07 \\
$\quad$ Hypertension & 0.88 & $0.50-1.55$ & .66 \\
$\quad$ Hyperlipidemia & 1.01 & $0.63-1.93$ & .74 \\
$\quad$ Diabetes & 0.93 & $0.72-1.68$ & .81 \\
Multivariate analysis & & & \\
$\quad$ Period, March & 0.32 & $0.14-0.74$ & .008 \\
$\quad$ 2003 June 2005 & & & \\
$\quad$ Presence of grade non-A & 1.85 & $1.05-3.24$ & .007 \\
$\quad$ Ejection fraction $<40 \%$ & 1.84 & $0.98-3.40$ & .055 \\
\hline
\end{tabular}

ITA, Internal thoracic artery.

to rationalize the use of the flow grading system in discussing an optimal strategy for graft arrangement because there was no previous report that had been performed to delineate significant correlations between the "bypass flow" in the early angiography and the "graft patency" in the follow-up angiography after totally arterial off-pump CABG with the composite and sequential grafts. Early occlusion caused by a technical problem, which might be the most significant bias, was eliminated by the early angiography. The follow-up period in this study is considered sufficient and suitable for examining the influence of flow condition on the graft patency because physiologic changes in the luminal diameter were found at approximately 14 to 24 months $^{7-9}$ or earlier. ${ }^{22,24}$ The results of our current study demonstrated that bypass grafts of not only grade $\mathrm{C}$ but also grade $\mathrm{B}$ were prone to close the graft lumen within the intermediate term. Therefore the flow grading system could be considered suitable and useful for discussing the optimal strategy for graft arrangement of arterial materials.

We found that the significant predictors of grade non-A were native stenosis of $75 \%, 4$ or more distal anastomoses from a single ITA, RCA and LCX territories, and the end of the conduit. The implications of these results were as follows. The sufficient antegrade flow had a favorable effect on the intermediate-term patency of the arterial grafts. When we plan the graft configuration, especially for the multiple coronary branches in the RCA and LCX territories, we have to be conscious of the anticipated graft flow in the created bypass conduit. The most important factor in determining the antegrade flow was the appropriate pressure slope in the bypass conduit, being highest at the proximal portion of the conduit and lowest at the distal end. The Y-graft has 2 ends, and the K-graft has 3 ends, and competitive and reverse flow 
was commonly found at the end of the conduit anastomosed with the moderately stenotic branch. To achieve an adequate pressure slope for 2 or 3 ends is less easy than for 1 end of the I-graft. On the other hand, the Y-graft is advantageous in terms of increased flow capacity ${ }^{25}$ and availability to distant target branches compared with the I-graft. For the diagonal, LCX, and RCA branches, the Y-graft or K-graft might be preferred when all target branches have severe stenosis, the target diagonal branch is located at the anteroapical portion, or remarkable cardiomegaly exists. Therefore we carefully examine the indications for the Y-graft and K-graft.

Our current arrangement would be one of the simple and useful methods that can be adjusted for each coronary system. The risk of the injury during reoperation in the future is a possible disadvantage of the I-graft in a clockwise orientation. On the contrary, the evident advantage of the I-graft in clockwise orientation is that the total length of the I-graft to the LCX and RCA territories could be minimized compared with that in a counterclockwise orientation. In previous reports the right ITA to the left coronary artery, which also crosses the midline like the clockwise I-graft, is a generally accepted and often recommended procedure of choice. ${ }^{26}$ The clockwise I-graft is considered justifiable.

Selection of suitable candidates for this procedure would be a major concern. When graft nonfunction or occlusion at a relatively early period is highly predicted, an alternative strategy, such as aortocoronary bypass, hybrid therapy with drug-eluting stent implantation, and conservation of the arterial graft for the redo operation in the future, might be a reasonable option of choice. In our experience sequential anastomoses with more than 2 moderately stenotic coronary branches were highly associated with flow insufficiency and late occlusion. Aortocoronary bypass would be reasonable because it has higher pressure potential than the in situ ITA. $^{27}$

The present study has several limitations. First, the study is not randomized. Furthermore, the sample size of the late angiography is considered relatively small. The follow-up angiography was performed for $10.7 \%$ of the patients who were biased toward clinically evident graft failure. However, all 61 patients underwent both early and late angiographies. Early graft occlusion caused by obviously technical failure, which might be the most significant bias, was eliminated.

Second, the quality of the target branch, the amount of myocardium, peripheral vascular resistance in the myocardial tissue, and flow demands can also have important roles in the coronary perfusion. However, we do not have reliable methods for quantifying each of these factors.

The third limitation is regarding the capacity of the ITA graft. The margin of the pressure potential of the in situ ITA might also play an important role in the occurrence of competitive and reverse flow. ${ }^{28}$ However, there is no alternative graft material for the ITA graft.

The fourth limitation might be the subject of the reproducibility of the flow grading system. Grades $\mathrm{O}$ and $\mathrm{C}$ are relatively easy to designate. Assigning grade $\mathrm{B}$ might be less so. Grade B probably includes both insufficient graft flow because of the strength of the native coronary flow and because of poor vascularity with high resistance in the severely impaired myocardium. Although no bypass graft might be required for the latter, we could not separately predict the insufficient antegrade flow caused by the critically damaged vasculature. In the present series there was no anastomotic stenosis, which restricted the blood flow and caused grade B bypass flow. In spite of these factors, the flow grade and angiographic data were prospectively collected and significantly correlated with the graft patency and clinical outcome. We therefore believe that the results of this study at least imply meaningful suggestions for establishing an optimal strategy for graft arrangement in the future.

In conclusion, the flow grading system was considered feasible as a criterion used for evaluation and comparison of the graft arrangements. Because the sufficient antegrade flow had a favorable effect on the durable patency of the arterial grafts, graft arrangement should be adjusted for each patient's coronary system to minimize competitive and reverse flow and to enhance the advantage of the arterial materials.

We thank Dr Yoshiko Kada for her assistance with the statistical analysis.

\section{References}

1. Lemma M, Mangini A, Gelpi G, Innorta A, Spina A, Antona C. Is it better to use the radial artery as a composite graft? Clinical and angiographic results of aorto-coronary versus Y-graft. Eur J Cardiothorac Surg. 2004;26:110-7.

2. Iaco AL, Teodori G, Giammarco GD, et al. Radial artery for myocardial revascularization: long-term clinical and angiographic results. Ann Thorac Surg. 2001;72:464-9.

3. Maniar HS, Sundt TM, Barner HB, et al. Effect of target stenosis and location on radial artery graft patency. $J$ Thorac Cardiovasc Surg. 2002;123:45-52.

4. Royse AG, Royse CF, Tatoulis J, et al. Postoperative radial artery angiography for coronary artery bypass surgery. Eur J Cardiothorac Surg. 2000;17:294-304.

5. Seki T, Kitamura S, Kawachi K, et al. A quantitative study of postoperative luminal narrowing of the internal thoracic artery graft in coronary artery bypass surgery. J Thorac Cardiovasc Surg. 1992;104: 1532-8.

6. Al-Bustami MH, Amrani M, Chester AH, Ilsley CJ, Yacoub M. In vivo early and mid-term flow-mediated endothelial function of the radial artery used as a coronary bypass graft. $J$ Am Coll Cardiol. 2002;39:573-7.

7. Siebenmann R, Egloff L, Hirzel H, Rothlin M, Studer M, Tartini R. The internal mammary artery "string phenomenon." Analysis of 10 cases. Eur J Cardiothorac Surg. 1993;7:235-8.

8. Hashimoto $\mathrm{H}$, Isshiki $\mathrm{T}$, Ikari $\mathrm{Y}$, et al. Effects of competitive flow on arterial graft patency and diameter. Medium-term postoperative follow-up. J Thorac Cardiovasc Surg. 1996;111:399-407. 
9. Bezon E, Choplain JN, Maguid YA, Aziz AA, Barra JA. Failure of internal thoracic artery grafts: conclusions from coronary angiography mid-term follow-up. Ann Thorac Surg. 2003;76:754-9.

10. Tector AJ, Amundsen S, Schmahl TM, Kress DC, Peter M. Total revascularization with T grafts. Ann Thorac Surg. 1994;57:33-9.

11. Christensen JB, Lund JT, Kassis E, Kelbaek H. Complete arterial coronary revascularization using conduit for double thoracic artery inlet flow: arterial sling operation. Eur J Cardiothorac Surg. 2002;21: 391-4.

12. Wendler $\mathrm{O}$, Hennen $\mathrm{B}$, Markwirth $\mathrm{T}$, et al. $\mathrm{T}$ grafts with the right internal thoracic artery to left internal thoracic artery versus the left internal thoracic and radial artery: flow dynamics in the internal thoracic artery main stem. J Thorac Cardiovasc Surg. 1999;118:841-8.

13. Nakajima H, Kobayashi J, Tagusari O, Bando K, Niwaya K, Kitamura S. Competitive flow in arterial composite grafts and effect of graft arrangement in off-pump coronary revascularization. Ann Thorac Surg. 2004;78:481-6.

14. Cameron A, Davis KB, Green G, Schaff HV. Coronary bypass surgery with internal thoracic artery grafts-effects on survival over a 15 -year period. N Engl J Med. 1996;334:216-9.

15. Rizzoli G, Schiavon L, Bellini P. Does the use of bilateral internal mammary artery (IMA) grafts provide incremental benefit relative to the use of a single IMA graft? A meta analysis approach. Eur J Cardiothorac Surg. 2002;22:781-6.

16. Lytle BW, Blackstone EH, Sabik JF, Houghtaling P, Loop FD, Cosgrove DM. The effect of bilateral internal thoracic artery grafting on survival during 20 postoperative years. Ann Thorac Surg. 2004;78: 2005-14.

17. Nakajima H, Kobayashi J, Tagusari O, Bando K, Niwaya K, Kitamura S. Functional angiographic evaluation of individual, sequential, and composite arterial grafts. Ann Thorac Surg. 2006;81:807-14.

18. Muneretto C, Negri A, Manfredi J, et al. Safety and usefulness of composite grafts for total arterial myocardial revascularization: a prospective randomized study. $J$ Thorac Cardiovasc Surg. 2003;125:826-35.

19. Weinschelbaum EE, Gabe ED, Macchia A, Smimmo R, Suarez LD. Total myocardial revascularization with arterial conduits: radial artery combined with internal thoracic arteries. J Thorac Cardiovasc Surg. 1997;114:911-6.

20. FitzGibbon GM, Burton JR, Leach AJ. Coronary bypass graft fate. Angiographic grading of 1400 consecutive grafts early after operation and 1132 after one year. J Thorac Cardiovasc Surg. 1978;57:1070-4.

21. FitzGibbon GM, Leach AJ, Keon WJ, Burton JR, Kafka HP. Coronary bypass graft fate. J Thorac Cardiovasc Surg. 1986;91:773-8.

22. Tagusari O, Kobayashi J, Bando K, Niwaya K, Nakajima H, Ishida M, et al. Early adaptation of the left internal thoracic artery as a blood source of Y-composite radial artery grafts in off-pump coronary artery bypass grafting. Heart Surg Forum. 2003;6:E93-8.

23. Izumi $\mathrm{C}$, Hayashi $\mathrm{H}$, Ueda $\mathrm{Y}$, et al. Late regression of left internal thoracic artery graft stenosis at the anastomotic site without intervention therapy. J Thorac Cardiovasc Surg. 2005;130:1661-7.

24. Parvaiz I, Lund JT, Kelbek H. The arterial sling operation: one year follow-up. Ann Thorac Surg. 2005;80:1375-80.

25. Royse AG, Royse CF, Groves KL, Yu G. Blood flow in composite arterial graft and effect of native coronary flow. Ann Thorac Surg. 1999;68:1619-22.

26. Schmidt SE, Jones JW, Thornby JI, Miller CC 3rd, Beall AC Jr. Improved survival with multiple left-sided bilateral internal thoracic artery grafts. Ann Thorac Surg. 1997;64:9-14.

27. Tedoriya T, Kawasuji M, Sakakibara N, Ueyama K, Watanabe Y. Pressure characteristics in arterial grafts for coronary bypass surgery. Cardiovasc Surg. 1995;3:381-5.

28. Jones EL, Lattouf OM, Weintrauf W. Catastrophic consequence of internal mammary artery hypoperfusion. $J$ Thorac Cardiovasc Surg. 1989;98:902-7. 